\title{
Remarkable Magnetic Properties of Co-doped ZnO Nanorods Array at Room Temperature Originated from Vertical Growth on Zn Foil
}

\author{
Li Yingying1, Dong Xiang ${ }^{2}$, Zhang Haiqian ${ }^{3}$ \\ ${ }^{1}$ Staff Room of Emergency Rescue, Public Security Fire Force College, Kunming 650208, China; ${ }^{2}$ National Engineering Researching Centre \\ of Waste Resources, Kunming University of Science and Technology, Kunming 650093, China; ${ }^{3}$ Nanjing University of Aeronautics and
} Astronautics, Nanjing 210016, China

\begin{abstract}
Large-area arrays of highly oriented Co-doped $\mathrm{ZnO}$ nanorods with hexagonal structure were grown on $\mathrm{Zn}$ substrates by single-step hydrothermal process. Structure analysis indicates that the as-prepared products have wurtzite structure, and no other secondary phase is found in the nanorods. The intensity of UV emission peak decreases with the increase of Co doping concentration. When $\mathrm{Co}$ is doped into $\mathrm{ZnO}$ lattice, oxygen vacancies and $\mathrm{Zn}$ interstitials are created. The concentration of these defects increases with rise of the Co concentration. Magnetic measurement reveals that the Co doped $\mathrm{ZnO}$ nanorod arrays exhibit obvious room-temperature ferromagnetic behavior with a large coercive field $H_{\mathrm{c}}$ of $52.8 \mathrm{kA} / \mathrm{m}$, which makes them potentially useful as building components for spintronics.
\end{abstract}

Key words: semiconductor; magnetic material; nanorod array; ZnO; hydrothermal

Diluted magnetic semiconductors (DMSs) have attracted considerable research interest in recent years due to their great potential applications in spintronic devices, such as spin field-effect transistors, non-volatile memory devices and quantum computer ${ }^{[1,2]}$. A key work to realize spintronic devices is to develop ferromagnetic DMSs with a Curie temperature above room temperature. Transition metal-doped $\mathrm{ZnO}$ DMSs have been extensively investigated since theoretic studies of Dietl et al. predicted their Curie temperature $\left(T_{\mathrm{c}}\right)$ to be above room temperature in $2000{ }^{[3]}$. Following the original research by Ueda et al. ${ }^{[4]}$, many reports have been given about Co doped $\mathrm{ZnO}$ thin films exhibiting ferromagnetism with $\mathrm{Tc}$ above room temperature. $\mathrm{Wu}$ et al. ${ }^{[5]}$ prepared $\mathrm{Zn}_{1-x} \mathrm{Co}_{x} \mathrm{O}$ nanowires using chemical vapor deposition (CVD) methods. Chen et al. ${ }^{[6]}$ reported that room temperature ferromagnetism was observed in Co doped $\mathrm{ZnO}$ nanoneedle array prepared by pulsed laser deposition. L. Q. Liu et al. ${ }^{[7]}$ reported the room temperature ferromagnetism of $\mathrm{Zn}_{1-x}(\mathrm{FeCo})_{x} \mathrm{O}$ nanowires synthesized via a CVD growth method.

Recently, solution growth methods, for example, the bottom-up approach is becoming attractive to grow semiconducting magnetic nanostructures as they are expected to allow better control over chemical composition and dopant speciation compared to those of the physical methods. The chemical synthesis, in addition to being cost-effective, also offers advantages such as bulk synthesis and easy processing. Although there are a number of reports on the chemical synthesis of $\mathrm{ZnO}$ nanostructures, only few of them are related to the synthesis of doped nanostructure of $\mathrm{ZnO}$. Yang et al. ${ }^{[8]}$ reported the synthesis of Co-doped $\mathrm{ZnO}$ nanorods using the hydrothermal method. Wang et al. ${ }^{[9]}$ reported a two-step chemical method for the synthesis of Co-doped singlecrystalline $\mathrm{ZnO}$ nanorods. The first step involved the preparation of $\mathrm{ZnO}$ nanoparticles (seeds), which acted as nucleating centers for nanorods, and in the second step nanorods were grown from the solution. In the chemical

Received date: January 20, 2015

Corresponding author: Li Yingying, Ph. D., Associate Professor, Staff Room of Emergency Rescue, Public Security Fire Force College, Kunming 650208, P. R. China, Tel: 0086-871-67210444-8150, E-mail: waiwailyy@163.com

Copyright (C) 2016, Northwest Institute for Nonferrous Metal Research. Published by Elsevier BV. All rights reserved. 
methods reported so far, the final products were obtained in powder form. Hence, there is a need to further process these powders so as to prepare their films for making devices. Nowadays, substrate-anchored thin film with oriented nanostructures are often more desirable for applications. Three-dimensional (3D) arrays of nanostructured materials have been widely introduced to enable to improve unique performances in electronics ${ }^{[10]}$, optical devices ${ }^{[11]}$, light emitting diodes ${ }^{[12]}$, and so on. The low dimensional, wide band gap $(3.37 \mathrm{eV})$ semiconductor-zinc oxide $(\mathrm{ZnO})$ with large excition binding energy $(60 \mathrm{meV})$ at room temperature has been so far applied in many aspects. Particularly, one dimensional $\mathrm{ZnO}$ oriented nanostructures are confirmed to be able to further enhance the performances of various devices, including field emission flat panel displays ${ }^{[13]}$, shorewavelength lasers ${ }^{[14]}$, solar cell ${ }^{[15]}$ and chemical sensors ${ }^{[16]}$. However, there are few researches on magnetic materials based on oriented $\mathrm{ZnO}$ nanostructure arrays. In particular, one-step template-free synthesizing route for one-dimensional $\mathrm{ZnO}$ array is still a significant challenge for researchers. In this paper, we reported a single-step simple wet chemical process to directly produce films of Co-doped $\mathrm{ZnO}$ nanorod arrays on zinc substrate in an aqueous medium. Zinc substrate can not only act as the carrier of the nanorods arrays, but also be the excellent conductor, which ensure the good ohmic contact between the $\mathrm{ZnO}$ nanorods and $\mathrm{Zn}$ substrate. At the same time, the $\mathrm{ZnO}$ nanorods film layer in-situ-generated on the zinc foil surface can improve the interface adhesive force.

\section{Experiment}

All chemicals were analytical-grade reagents and purchased from Shanghai Chemical Reagent Corp. The zinc foil (99.99\% purity) with a size of $2.5 \mathrm{~cm} \times 2.0 \mathrm{~cm} \times 0.1 \mathrm{~cm}$ was polished, washed by acetone, ethanol and distilled water for several times, and dried in an oven. Cobalt acetate $\left[\mathrm{Co}(\mathrm{Ac})_{2} \cdot \mathrm{H}_{2} \mathrm{O}\right]$ and tetramethylammonium hydroxide (TMAOH, 25\%) were used as reactants without further purification.

The $\mathrm{Zn}$ foil substrates were put up-side down into a $50 \mathrm{~mL}$ Teflon-lined stainless steel autoclave within $40 \mathrm{~mL}$ aqueous solution of $0.3 \mathrm{~mol} / \mathrm{L} \mathrm{TMAOH}$ and required amount $\mathrm{Co}(\mathrm{Ac})_{2} \cdot \mathrm{H}_{2} \mathrm{O}$. The autoclave was heated to $170{ }^{\circ} \mathrm{C}$ for $12 \mathrm{~h}$ in the oven. After the reaction, the specimens were completely washed with absolute ethanol and Milli-Q water for several times, and then dried in vacuum at $60{ }^{\circ} \mathrm{C}$ for $8 \mathrm{~h}$.

The morphologies of the as-synthesized Co-doped $\mathrm{ZnO}$ nanorods arrays were observed by field-emission scanning electron microscopy (FE-SEM, LEO1550). The crystal structures of the obtained samples were characterized by X-ray diffraction with graphite monochromatized $\mathrm{CuK} \alpha$ radiation (BrukerD8, $\lambda=0.15405 \mathrm{~nm}$ ). Photoluminescence measurement was carried out by employing a CARY Eclipse Fluorescence spectrum. The Raman spectra were collected at room temperature with a confocal Raman microscope
(NT-MDT NTEGRA Spectra) using a $514 \mathrm{~nm}$ laser as the excitation source. A vibrating sample magnetometer (VSM) was used to study the magnetic properties.

\section{Results and Discussion}

In the present experiment, we couldn't confirm the quantity of the zinc atoms involved in the reaction, so we assumed all the TMAOH reacted with $\mathrm{Zn}$ substrates and calculated the quantity of the $\mathrm{Zn}^{2+}$. Then the $\mathrm{Co}(\mathrm{Ac})_{2} \cdot \mathrm{H}_{2} \mathrm{O}$ were added in the solution with the mass fractions $1 \%, 5 \%$, and $10 \%$ of the $\mathrm{Zn}^{2+}$. The samples are denoted as $\mathrm{ZnO}: 1 \mathrm{wt} \% \mathrm{Co}$, and $\mathrm{ZnO}: 5 \mathrm{wt} \% \mathrm{Co}$, $\mathrm{ZnO}: 10 \mathrm{wt} \% \mathrm{Co}$.

Figs.1a 1g show the SEM images of the $\mathrm{ZnO}$ nanorods arrays with different Co doping concentrations and the pure $\mathrm{ZnO}$ nanorods arrays. Remarkably, the uniformity of the nanorods over a large area is obviously shown in a top view image, taken in a low magnification of the nanorods arrays (Fig.1a, 1c, 1e). Uniform growth of nanomaterials on large scale is important to nanodevice fabrication. The highmagnification FE-SEM images of the arrays (Fig.1b, 1d, 1f) suggest that the nanorods of high density grow nearly vertically from the substrates. The diameters of the nanorods in a hexagonal shape with the pencil shape tip are estimated to

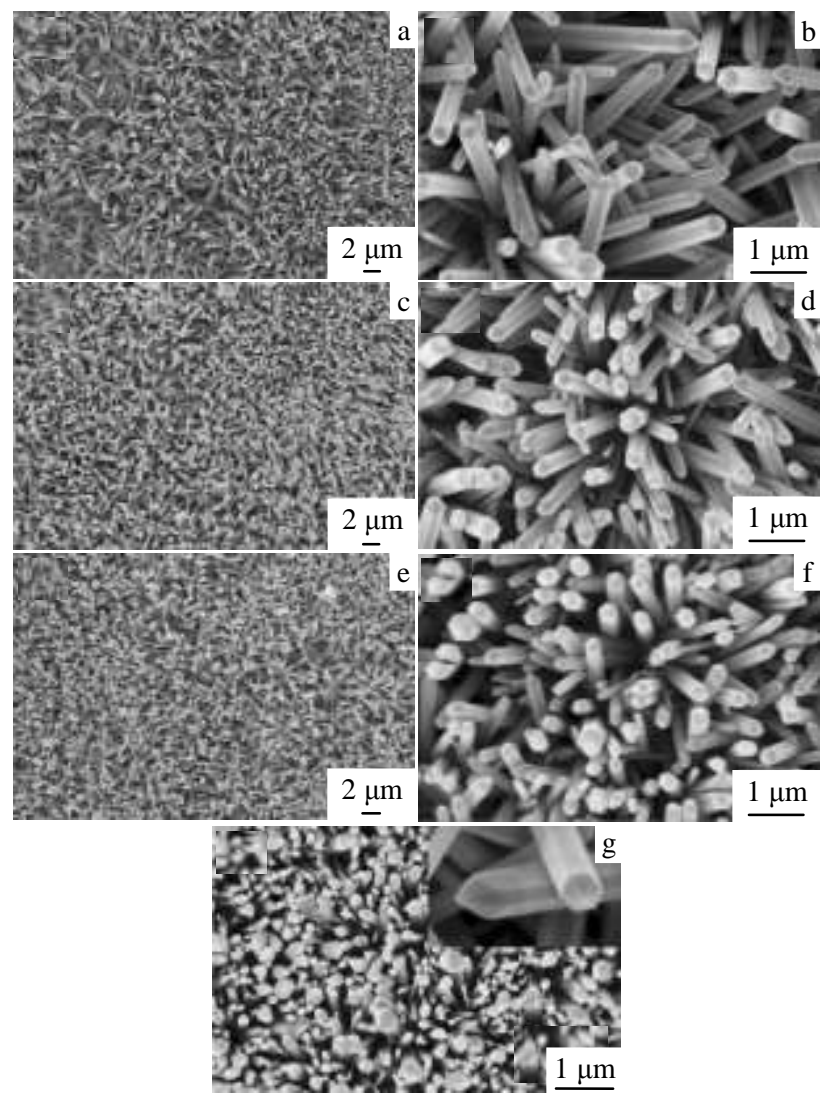

Fig.1 SEM images of $\mathrm{ZnO}$ nanorods arrays with different $\mathrm{Co}$ doping concentrations and pure $\mathrm{ZnO}$ nanorods arrays: (a, b) $\mathrm{ZnO}: 1 \mathrm{wt} \% \mathrm{Co}$; (c, d) $\mathrm{ZnO}: 5 \mathrm{wt} \% \mathrm{Co}$; (e, f) $\mathrm{ZnO}$ : $10 \% \mathrm{Co} ;(\mathrm{g})$ pure $\mathrm{ZnO}$ nanorods arrays 
be $200 \sim 300 \mathrm{~nm}$. The lengths of the nanorods are more than 5 $\mu \mathrm{m}$. Through comparing the Fig.1b, Fig.1d, Fig.1f and Fig.1g, it is found that the morphologies of the $\mathrm{Co}$ doped $\mathrm{ZnO}$ nanorods do not change significantly.

The XRD patterns of $\mathrm{ZnO}$ nanorods arrays doped with different concentrations of Co ions are shown in Fig.2. All diffraction peaks are well indexed to the standard diffraction pattern of hexagonal phase $\mathrm{ZnO}$, implying a wurtzite structure with high crystallinity, without any additional impurity phases, thereby indicating that the Co ions successfully occupy the lattice sites rather than interstitial ones ${ }^{[17]}$. It also can be seen that with increasing of concentration of $\mathrm{Co}$, the peak position of $\mathrm{Zn}_{1-x} \mathrm{Co}_{x} \mathrm{O}$ is shifted to higher angles, which indicates the decrease of lattice parameters $a$ and $c^{[18]}$. These phenomena presumably result from the substitution of Co ions with a small ionic radius of $0.058 \mathrm{~nm}$ for $\mathrm{ZnO}(0.060 \mathrm{~nm}){ }^{[19]}$. This also can be proved that the $\mathrm{Co}$ ions are replaced into the $\mathrm{ZnO}$ lattice.

Fig.3 presents the room temperature photoluminescence (PL) spectra of the as-grown Co-doped $\mathrm{ZnO}$ nanorods arrays and pure $\mathrm{ZnO}$ nanorods arrays by a Xe lamp (325 nm wavelength) as the source of excitation. The pure $\mathrm{ZnO}$ nanorods arrays exhibit a strong luminescence peak centered at $386 \mathrm{~nm}$, which represents the near-band-edge emission. In addition, there is no other emission peak except a weaker blue luminescence emission peak around $443 \mathrm{~nm}$. Compared with the undoped $\mathrm{ZnO}$, the $\mathrm{UV}$ emission peak intensity decreases in Co-doped $\mathrm{ZnO}$ nanorods arrays with the increase of $\mathrm{Co}$ doping concentration, which perhaps are attributed to non-radiative recombination process. Besides, the band edge emission peak width FWHM (full width at half maximum) increases as the Co doping concentration increases. The broadening of the band edge PL emission may be explained in terms of potential fluctuations resulting from the random distribution of $\mathrm{Co}$ dopants in $\mathrm{ZnO}{ }^{[20]}$. The microscopic inhomogeneity of the dopant concentration causes the potential fluctuation or tail states of band edges, leading to broadening of the band edge emission.

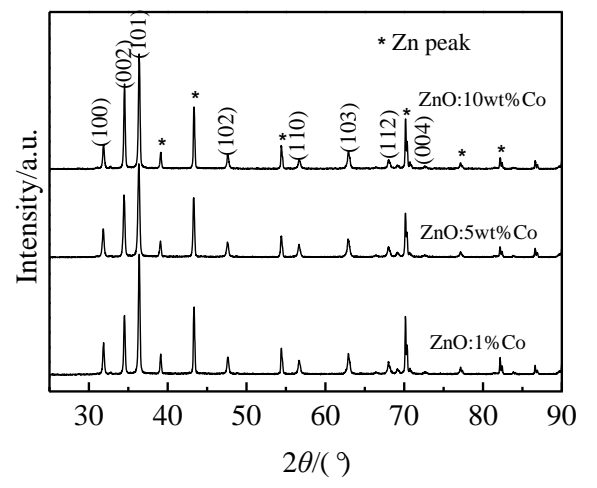

Fig.2 XRD patterns of the $\mathrm{ZnO}$ nanorods arrays with different Co doping concentrations

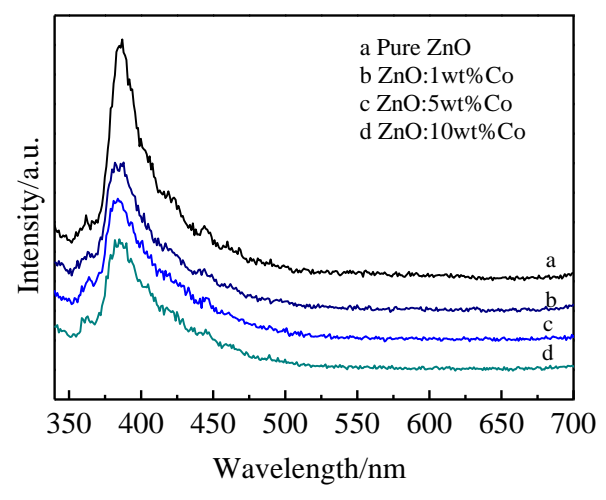

Fig.3 PL spectra of the as-grown Co-doped $\mathrm{ZnO}$ nanorods arrays and pure $\mathrm{ZnO}$ nanorods arrays, recorded at room temperature, $\lambda_{\mathrm{ex}}=325 \mathrm{~nm}$

The pure $\mathrm{ZnO}$ nanorods arrays and Co-doped $\mathrm{ZnO}$ nanorods arrays have been investigated by Raman spectrum, as shown in Fig.4. For the pure $\mathrm{ZnO}$, the sharpest and strongest peak located at $437 \mathrm{~cm}^{-1}$ can be assigned to the high-frequency branch of $E_{2 \mathrm{H}}$ mode of $\mathrm{ZnO}$, which is the strongest mode in crystal structure. The peaks at 328 and 374 $\mathrm{cm}^{-1}$ are assigned to the second-order vibration mode $E_{2 \mathrm{H}}-E_{2 \mathrm{~L}}$ of $\mathrm{ZnO}$ and the transverse-optical mode with $\mathrm{A}_{1}$ symmetry mode $\left[\mathrm{A}_{1}(\mathrm{TO})\right]$, respectively. In contrast to Raman spectra of $\mathrm{ZnO}$, the Raman-scattering peak positions of $\mathrm{ZnO}: 1 \mathrm{wt} \% \mathrm{Co}$, $\mathrm{ZnO}: 5 \mathrm{wt} \% \mathrm{Co}$ and $\mathrm{ZnO}: 10 \mathrm{wt} \% \mathrm{Co}$ do not change, which is consistent with XRD results, where Co doping does not change the samples structure ${ }^{[21]}$, and except for the character peak of $\mathrm{ZnO}$, no other peaks related impurity phases are obtained. In addition, with the increment of doping content, the intensity of the peak at $570 \mathrm{~cm}^{-1}$ increases, which is assigned to the longitudinal-optical mode with $\mathrm{ZnO}\left[\mathrm{A}_{1}(\mathrm{LO})\right]$. Generally, this mode is induced by host lattice defects, such as oxygen vacancies and $\mathrm{Zn}$ interstitials. When $\mathrm{Co}^{2+}$ is doped into $\mathrm{ZnO}$ lattice, oxygen vacancies and $\mathrm{Zn}$ interstitials are created. Furthermore, the concentration of these defects increases with

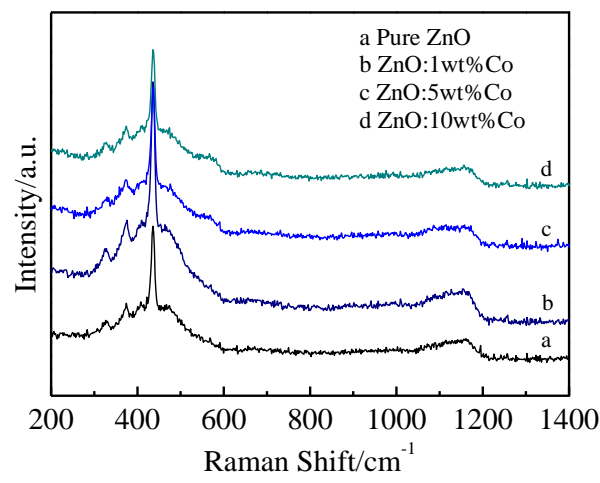

Fig.4 Raman spectra of the pure $\mathrm{ZnO}$ nanorods arrays and Co-doped $\mathrm{ZnO}$ nanorods arrays, recorded at room temperature, $\lambda_{\mathrm{ex}}=325 \mathrm{~nm}$ 
increasing of the Co concentration, which is approved by the enhanced intensity of the peak at $570 \mathrm{~cm}^{-1}$ [22]

The magnetic properties of the $\mathrm{Co}$ doped $\mathrm{ZnO}$ nanorods arrays were investigated using a vibrating sample magnetometer (VSM). Fig.5 shows the magnetic field dependence of the magnetization ( $M-H$ curves) for $\mathrm{ZnO}, \mathrm{ZnO}: 5 \mathrm{wt} \% \mathrm{Co}$ and $\mathrm{ZnO}: 10 \mathrm{wt} \% \mathrm{Co}$ at room temperature. The diamagnetic contribution from the sample holder has been subtracted from the data. We can see that the pure $\mathrm{ZnO}$ nanorods arrays show diamagnetic behavior whereas all Co-doped $\mathrm{ZnO}$ nanorods show ferromagnetic behavior at room temperature. From the hysteresis loop, the saturation magnetization is found to increase with the increase of Co doping concentration. For $\mathrm{ZnO}$ : $10 \mathrm{wt} \%$ Co sample, hysteresis loops with a coercive field $H_{\mathrm{c}}$ of $52.8 \mathrm{kA} / \mathrm{m}$ can be observed at $300 \mathrm{~K}$ from curve $\mathrm{c}$ in Fig.5. The saturation magnetization of the sample is about $6.105 \times 10^{-3} \mathrm{~A} \cdot \mathrm{m}^{2} / \mathrm{kg}$. There are two possible origins of the ferromagnetism in the Co doped $\mathrm{ZnO}$ system. One is due to the small secondary phases such as Co-metal clusters or Co-oxide precipitates. In the present studies, metallic Co and $\mathrm{CoO}$ are unlikely the source of this ferromagnetism because no detectable $\mathrm{Co}$ or $\mathrm{CoO}$ phases could be observed in the XRD patterns. According to the XRD patterns, absorption spectra and Raman spectra results, $\mathrm{Co}^{2+}$ ions are successfully incorporated into the wurtzite lattice at the $\mathrm{Zn}^{2+}$ sites, and then the possibility of Co precipitations can be ruled out. We suggest that the origin of the observed ferromagnetic order in the Co doped $\mathrm{ZnO}$ nanorods arrays can be explained using the carriers-mediated mechanism, by the RKKY type exchange mediated by the conduction carriers ${ }^{[23]}$. The conduction carriers in $\mathrm{ZnO}$ can be the native defects such as oxygen vacancy and interstitial zinc, which can be easily formed in doped $\mathrm{ZnO}$. Recently, some works indicate that the as-grown $\mathrm{ZnO}$ nanowires are dominated by zinc interstitial, which is a shallow-level donor, and make the synthesized $\mathrm{ZnO}$ an n-type semiconductor ${ }^{[24]}$. As a result, the observed magnetic behavior may be attributed to the exchange interaction between free delocalized carriers (hole or electron from the valence band)

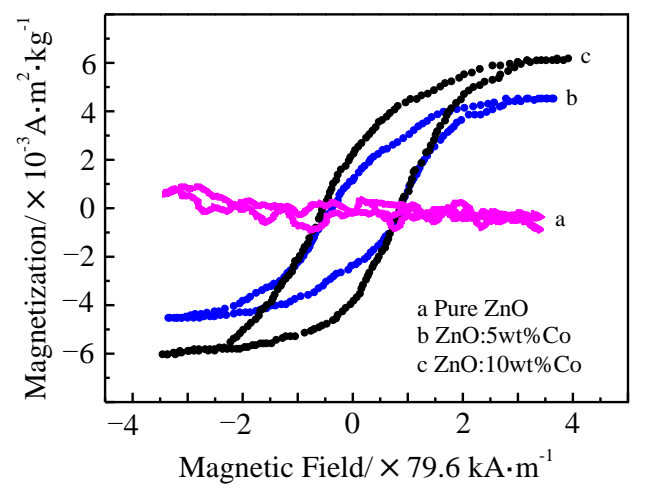

Fig.5 $M$ - $H$ curves of pure $\mathrm{ZnO}$ nanorods arrays and Co-doped $\mathrm{ZnO}$ nanorods arrays at $300 \mathrm{~K}$ and the localized magnetic dipole moments of the magnetic ions (the localized $\mathrm{d}$ spins on the Co ions). The free carrier concentration has an effect on the ferromagnetism of $\mathrm{Zn}_{1-x} \mathrm{Co}_{x} \mathrm{O}$. The Raman scattering study shows that defects in $\mathrm{Co}$ doped $\mathrm{ZnO}$ nanorods arrays increase with the increment of Co content (see Fig.4). Therefore, although more studies have to be done to understand the connection between the defects and the room-temperature ferromagnetism in transition metal-doped $\mathrm{ZnO}$, present study has clearly shown that the defect is an important factor influencing the room temperature ferromagnetism.

\section{Conclusions}

1) Large scale densely packed and vertically oriented pencil like nanorods arrays can be grown on zinc substrate.

2) The as-prepared products have wurtzite structure, and no other secondary phase is found in the nanorods.

3) $\mathrm{Co}^{2+}$ ions can substitute $\mathrm{Zn}^{2+}$ sites.

4) The doped nanorods arrays have obvious room temperature ferromagnetic behavior. The observed magnetic behavior may be attributed to the exchange interaction between free delocalized carriers (hole or electron from the valence band) and the localized magnetic dipole moments of the magnetic ions (the localized d spins on the Co ions).

\section{References}

1 Sarma S D. Nature Material[J], 2003, 2: 292

2 Malajovich I, Berry J J, Samarth N et al. Nature[J], 2001, 411: 770

3 Dietl T, Ohno H, Matsukura F et al. Science[J], 2000, 287: 1019

4 Ueda K, Tabata H, Kawai T. Applied Physics Letters[J], 2001, 79: 988

5 Wu Jih-Jen, Liu Saichang, Yang Ming-Hsun et al. Applied Physics Letters[J], 2004, 85: 1027

6 Chen J J, Yu M H, Zhou W L et al. Applied Physics Letters[J], 2005, 87: 173119

7 Liu L Q, Xiang B , Zhang X Z et al. Applied Physics Letters[J], 2006, 88: 63104

8 Yang L W, Wu X L, Qiu T et al. Journal of Applied Physics[J], 2006, 99: 74303

9 Wang H, Wang H B, Yang E J et al. Nanotechnology[J], 2006, 17: 4312

10 Tian Bozhi, Cohen-Karni Tzahi, Qing Quan et al. Science[J], 2010, 329: 830

11 Liang Dong, Huo Yijie, Kang Yangsen et al. Advanced Energy Materials[J], 2012, 2: 1150

12 Lee Jung Min, Choung Jae Woong, Yi Jaeseok et al. Nano Letters[J], 2010, 10: 2783

13 Lee C J, Lee T J, Lyu S C et al. Applied Physics Letters[J], 2012, 81: 3648

14 Huang Michael H, Mao Samuel, Feick Henning et al. Science[J], 2001, 292: 1897

15 Law M, Greene L E, Johnson J C et al. Nature Materials[J], 
2005, 4: 455

16 Trivikrama Rao G S, Tarakarama Rao D. Sensors and Actuators B: Chemical[J], 1999, 55: 166

17 Cheng Chuanwei, Xu Guoyue, Zhang Haiqian et al. Materials Letters[J], 2008, 62: 3733

18 Yoo Y Z, Fukumura T, Jin Zhengwu et al. Journal of Applied Physics[J], 2001, 90: 4246

19 Samanta K, Bhattacharya P, Katiyar R S. Applied Physics Letters [J], 2005, 87: 101903

20 Schubert E F, Goepfert I D, Grieshaber W et al. Applied Physics
Letters[J], 1997, 71: 921

21 Zhou Xueyun, Ge Sshihui, Yao Dongsheng et al. Journal of Alloys and Compounds[J], 2008, 463: 9

22 Samanta K, Bhattacharya P, Katiyar R S. Physical Review B[J], 2007, 75: 35208

23 Sato Kazunori, Katayama-Yoshida Hiroshi. Japanese Journal of Applied Physics[J], 2001, 40: 334

24 Zhang S B, Wei Su-Huai, Zunger Alex. Physical Review $B[\mathrm{~J}]$, 2001, 63: 75205

\title{
垂直生长于锌基底的 $\mathrm{Co}$ 掺杂 $\mathrm{ZnO}$ 纳米棒阵列显著室温铁磁性能
}

\author{
李荣藩 ${ }^{1}$, 董 祥 $^{2}$ 张海黔 $^{3}$ \\ (1. 公安消防部队昆明指挥学校, 云南 昆明 650208)
}

(2. 昆明理工大学 废弃物资源化国家工程研究中心, 云南 昆明 650093)

(3. 南京航空航天大学, 江苏 南京 210016)

\begin{abstract}
摘 要: 通过简单的水热合成法在锌片基底上一步制备了 $\mathrm{Co}$ 掺杂的 $\mathrm{ZnO}$ 纳米棒阵列。纳米棒在基底上均匀分布, 取向一致, 垂直于基 底大面积生长。样品结构均为六方纤锌矿结构, 具有高结晶质量, 不含其它杂相。随着 Co 掺杂浓度的增加, 紫外发射峰强度逐渐下降, 近带隙发射峰的半峰宽也较纯 $\mathrm{ZnO}$ 变宽。拉曼光谱显示 $\mathrm{Co}$ 的掺杂使纳米棒出现了氧空位和锌填隙本征缺陷。随着 $\mathrm{Co}$ 浓度的增加这些 缺陷也随之增加。掺杂纳米棒阵列的磁滞回线表明样品具有明显的铁磁特征, 并有较大的矫顽力 $H_{\mathrm{c}}=52.8 \mathrm{kA} / \mathrm{m}$ 。这种 $\mathrm{ZnO}$ 基稀磁半导 体纳米棒阵列是一种在自旋电子器件中具有应用潜力的纳米材料。
\end{abstract}

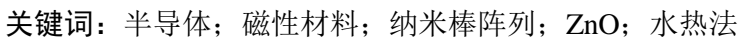

作者简介: 李荣漟, 女, 1982 年生, 博士, 副教授, 公安消防部队昆明指挥学校训练部应急救援教研室, 云南 昆明 650208 , 电话: 0871-67210444-8150,E-mail: waiwailyy@163.com 